\title{
Aging in Autism Spectrum Disorders: A Mini-Review
}

\author{
Francesca Happéa Rebecca A. Charlton ${ }^{\mathrm{b}, \mathrm{c}}$ \\ ${ }^{a}$ MRC Social, Genetic and Developmental Psychiatry Centre, Institute of Psychiatry, King's College London, and \\ ${ }^{b}$ Clinical Neuroscience, St George's, University of London, London, UK; ' ${ }^{2}$ Department of Psychiatry, University of \\ Illinois at Chicago, Chicago, III., USA
}

\section{Key Words}

Autism - Asperger syndrome - Pervasive developmental disorders $\cdot$ Adults $\cdot$ Aging $\cdot$ Old age

\begin{abstract}
This article addresses an important and barely researched topic: what happens to children with autism spectrum disorders when they grow old. We review the small published literature on aging in autism. We then consider the relevance of research on 'neurotypical' aging in core domains of autistic impairment: social cognition, executive function, cognitive style and memory. Research themes from the study of normal aging, including cognitive reserve, compensation, quality of life, loneliness and physical health are of relevance for future research on autism. Studies of aging in autism will be important not only to plan appropriate services, but also to shed light on the full developmental trajectory of this neurodevelopmental condition, and perhaps provide clues to neuropathology and etiology.
\end{abstract}

Copyright $\odot 2011$ S. Karger AG, Basel

\section{Autism and Autism Spectrum Disorders}

Autism is a relatively 'modern' diagnosis, originating in case reports by Kanner [1] and Asperger [2] in 1943 and 1944, respectively, who both borrowed Bleuler's term to describe the abnormal social development of the children they saw. There is no doubt that autism itself is not a modern phenomenon, and a number of earlier single or group reports can be found [3], as well as descriptions in non-scientific sources of individuals who would clearly meet current diagnostic criteria [4]. However, since the term 'autism' only came into clinical use in the 1940 s and more commonly from the 1960s onwards, the first cohort of identified children are only now entering old age.

Autism is now considered part of a spectrum of related conditions, all of which are marked by social and communicative deficits and the presence of rigid and repetitive behaviour and interests. Current diagnostic systems (DSM-IV, ICD-10) distinguish autism from Asperger syndrome on the basis of lack of language or intellectual delay in the latter, but the significance of this distinction is hotly debated. In practice, there is a vast range of manifestations of the core diagnostic features of autism spectrum disorders (ASD); different individuals (or the same individual over time) may be socially aloof, completely mute, and locked into repetitive rocking and hand flapping, or inappropriately over-friendly, highly verbal but incapable of distinguishing jokes from lies, and fascinated by abstruse astronomical facts. Taking the full autism spectrum into account, using current diagnostic criteria, approximately $1 \%$ of children are affected by ASD [5]. Estimates in adult populations support a similar preva-

\section{KARGER \\ Fax +41613061234 E-Mail karger@karger.ch} www.karger.com
(C) 2011 S. Karger AG, Base 0304-324X/12/0581-0070\$38.00/0

Accessible online at: www.karger.com/ger
Prof. Francesca Happé

MRC Social, Genetic and Developmental Psychiatry Centre

Institute of Psychiatry (PO 80), King's College London

De Crespigny Park, Denmark Hill, London SE5 8AF (UK)

Tel. +44207848 0873, E-Mail francesca.happe@ kcl.ac.uk 
lence, with $1.8 \%$ of males and $0.8 \%$ of females affected according to a UK household survey in 2007 [6].

Abnormalities in the 'triad' of ASD domains (social abnormality, communication impairments, rigid/repetitive behaviour) are typically present from infancy (under age 3 in current diagnostic criteria), but diagnosis may occur much later, especially in atypical or complex cases. In recent years, the numbers of individuals coming for first diagnosis of ASD in adulthood has greatly increased. Diagnosis of an adult presents a range of challenges, in particular obtaining accurate developmental history about the first 3 or 4 years of life after a significant passage of time, and when parents are often unavailable.

Diagnosis first in adulthood is often prompted by a diagnosis of autism in the offspring, and it is not unusual for a father to remark on his own Asperger traits as he reads up about his son's new diagnosis of autism. This reflects the strong genetic component in ASD; autism is thought to be among the most heritable of developmental disorders, although the precise genes involved have not been identified. Monozygotic twins show concordance rates of $60-90 \%$ (vs. $0-30 \%$ in dizygotic twins), and relatives of ASD probands often show subclinical features of ASD referred to as the 'broader autism phenotype'.

There have been extensive investigations into the neural basis of ASD, using structural and functional neuroimaging, and neuropathological work on a limited number of post-mortem specimens. Many abnormalities have been reported, among the better-replicated being reduced Purkinje cells in the cerebellar vermis, accelerated brain growth in infancy (with the suggestion of abnormal long-range connectivity), and increased platelet serotonin. Nothing is known about brain changes in old age in individuals with ASD [but see 7 for a review of brain findings in adulthood]. Mortality rates appear to be raised 2 - to 5 -fold in studies of middle-aged adult samples with ASD, with most deaths associated with epilepsy or accident $[8,9]$. It is unclear whether ASD itself affects life span, or whether the strong association with seizure disorders (affecting approximately $30 \%$ of those with ASD) and intellectual disability (25-50\%) account for raised mortality.

\section{Published Research on Aging in Autism}

Published work was searched using combinations of the following search terms: autism (or autistic, Asperger or pervasive developmental disorder), aging (ageing, old age, elderly), and adult. The resulting references were

Aging in Autism Spectrum Disorders broadly of three sorts: case studies reporting older individuals with ASD [10-12], discussion papers raising questions about aging and/or the diagnosis of ASD in older age [13-16], and papers reporting empirical data from surveys or studies of older individuals with ASD $[17,18]$.

Case study papers on older adults with ASD include a letter and article from authors at a specialist psychiatric referral service for older adults $[10,11]$. Five individuals (aged 66-84) were described who had been referred to services for other issues, including depression. These individuals demonstrated behaviour, cognitive profiles or patterns of social interaction, often throughout the life span, that led to the suggestion of an ASD diagnosis. The authors' note that many of these individuals were born prior to the original definition of Asperger syndrome, have largely had no prior contact with specialist services, but importantly may be receiving inappropriate treatment due to misdiagnoses in later life [10]. A brief report in Dutch [13] also discusses the difficulties of making ASD diagnosis in later life and the need for further research. These three papers were the only peer-reviewed articles on ASD in later life discovered by van Niekerk et al. [12] in their 2011 review, in which they discuss the challenges of diagnosing ASD in the elderly. These authors illustrate their points with three case studies of elderly individuals receiving their first diagnosis in a tertiary mental health clinic.

Povey et al. [15] recently published an overview paper raising the issue of aging in autism, discussing practical and policy implications, and highlighting the need for further research. They note, for example, the need to gather family history information about health issues while parents are still available, in order to identify future health risks (e.g. heart disease) in the individual with ASD. They also highlight the possible effects of long-term use of antipsychotic medication, common in adults with ASD, as an area needing research. An earlier article, by Wick and Zanni [16], also highlights the fact that service needs for adults with ASD are only now becoming apparent and that issues relating to aging remain largely unknown. The most recent review paper [14], following a meeting on autism and aging held in Newcastle in 2009, found only seven published papers on aging in people with autism; those reviewed here [10-13, 18, 19], plus a Dutch PhD thesis chapter by van der Palen [20]. Mukaetova-Ladinska et al. [14] concluded that 'the aging process of ASD remains ... underinvestigated and thus poorly understood'.

Very little has been published in terms of empirical group studies of ASD in old age. A recent report commis- 
sioned by the Welsh Assembly Government, attempted to collect such data using three approaches; on-line questionnaires, in-person interviews, and analyses of existing databases [17]. The on-line questionnaire study managed to gather data from only 29 individuals with (diagnosed or self-identified) ASD, most of whom were in their forties. These individuals, most with Asperger syndrome, reported problems with employment and both mental and physical health. In-person interviews were conducted with a further 11 individuals (aged 37-57) diagnosed with Asperger syndrome in adulthood, and showed a number of common themes in terms of concerns and problems with understanding and support received.

The third approach adopted by Stuart-Hamilton et al. [17] consisted of analysis of combined, existing data bases, and gave rise to an article reporting on 282 adults aged $50+$ with intellectual disability (ID), with or without additional ASD symptoms. Comparison of these older adults with $(\mathrm{n}=87$, mean age 59$)$ versus without $(\mathrm{n}=195$, mean age 61) ASD suggested that differences in behaviour problems, psychiatric disorders or quality of life were accounted for by differences in adaptive behaviour, rather than presence of ASD per se [18]. These findings match the conclusions of a critical review and synthesis of recent research on mental health in adults with ASD and/or ID [21] that there is little evidence to date that adults with ID and ASD are more vulnerable to psychiatric disorders than those with ID alone, once severity of intellectual impairment, adaptive behaviour and social skills are taken into account. In light of these findings, the research literature on aging in individuals with intellectual disability is likely to be of direct relevance to the study of aging in ASD.

A number of recent studies have suggested that many of the issues relating to typical age-related decline are also important for individuals with intellectual disabilities [e.g. 22]. Some studies have suggested that such individuals may demonstrate age-related cognitive decline at earlier ages or more rapidly that typical adults, although much of this work has included individuals with Down syndrome, who appear to be at increased risk for developing Alzheimer's disease. Importantly, many of the factors that seem to influence cognitive decline are not related to intellectual level, but to other comorbid factors including epilepsy, obesity, pain, falls, hypertension, diabetes, sedentary lifestyle as well as hearing and vision issues. Many authors suggest that in individuals with intellectual disabilities, an emphasis on physical health and independence may be beneficial and lead to healthier aging. This is also likely to prove relevant for individuals with ASD.
In addition to the above papers in scientific journals, three magazine articles discussing aging in ASD deserve mention. One, from Newsweek, describes the difficulties facing ASD individuals moving from childhood to adult services, and the lack of available support and resources [23]. A second, more relevant to this review, describes the concerns of the author for the ongoing care of his severely autistic brother [24]. As parents age, the care of individuals with ASD, whether on a daily basis or in selecting appropriate supported living, is likely to fall to siblings. The author very honestly describes not only his concern for the on-going care of his brother, but also his need to provide the care and support required as his parents age [24]. In both the academic and magazine articles described here, concerns are raised regarding provision of service for older adults with ASD, as well as problems with the perception and understanding of the needs of adults aging with what is often perceived as a childhood disorder.

The third article, in the Atlantic magazine, 'revisits' the subject of Kanner's first case-study of autism [25]. Donald was 10 years old when first described by Kanner in 1943; now in his late 70s he continues to live in the Mississippi community where he has spent much of his life. Although institutionalised in childhood (after a year his parents removed him from the institution against medical advice), Donald later graduated from high school, attended college and worked as a bank teller. Many of the positive factors in Donald's life can be attributed to the support of his family: his wealthy and well-educated parents, dissatisfied with his diagnosis, were prepared to ignore medical advice and able to pay to see the leading doctors of the day. Donald's employment was in the family bank, and a trust fund still supports his needs. Donald has also found a niche in the wider community; in his home town Donald's talent for maths is respected and his 'oddities' are accepted. Many of these oddities are typical of ASD: speech that is repetitive, social awkwardness, a preference for being alone and for routines. Some are special and idiosyncratic to Donald, such as assigning each individual he meets a unique number, maintained through their lifetime. Importantly, Donald has continued to develop skills throughout adulthood, learning how to play golf (aged 23), drive a car (aged 27), and travel independently (aged 36) to many countries but strictly for 6 days or fewer at a time! Learning and skill acquisition have not been studied in older adults with ASD, but Donald's case underlines the importance of continuing to provide opportunities for development throughout life. 
This brief review of the literature makes clear that very little is known about old age in autism. Indeed, a US multidisciplinary expert group convened in March 2010 to characterize gaps in knowledge regarding ASD in older adults and define future research directions, concluded that 'An understanding of the epidemiological, biological, psychological, and social aspects of ASDs in older adults is essential for preparing to meet their needs; however, studies on ASDs in these individuals are practically nonexistent' [Piven, Rabins, Betty-Kravis et al., submitted].

\section{Adult Trajectories in ASD}

In the absence of empirical research on old age in ASD, it is useful perhaps to review briefly what is known about the adult trajectory of this developmental disorder. There have been a number of fairly long-term follow-up studies of children diagnosed with autism. Howlin et al. [26] reported on outcome of 68 individuals diagnosed in childhood at the Maudsley Hospital in the 1950s to 1970s. At age 21-48 these individuals showed relatively poor outcome in the majority of cases, with few living independently, but outcome was strongly linked to intellectual level. Social and communication impairments persisted, as did restricted and repetitive behaviour. Billstedt et al. [27] report a population-based follow-up study of 120 individuals diagnosed with autism in childhood, and reevaluated 13-22 years later at ages 17-40. Outcome was rated as poor in $78 \%$ of the cases, with few attaining independence, and IQ was again a strong prognostic factor.

Childhood diagnosis of Asperger disorder appears to carry a better prognosis than autism, which may reflect better verbal ability or overall IQ in this group [28]. A follow-up study of 177 of Hans Asperger's original clinic cases (to mean age 42) suggests that outcome can be good in terms of both employment and relationships [29]. This follow-up also showed that ASD is not associated with higher rates of criminal conviction [30], important in the face of media reports of possible Asperger syndrome in high-profile violent offenders.

A key issue for follow-up studies of adults diagnosed in early childhood is that the diagnostic criteria for autism have broadened considerably since the first use of the term in the 1950s and the introduction of autism as a separate diagnostic category in DSM-III in 1980. Many children meeting current criteria for autism would not have met the criteria used in those days, and the categories of Asperger disorder and 'PDD-NOS' did not exist - hence older samples will reflect more severe cases, typically with more language impairment and intellectual disability. The outcome of such groups may tell us little about the likely outcome of children with ASD diagnosed in this decade, who also receive more targeted educational approaches, earlier intervention, and better information and support in general.

A study of 120 adults (16-60 years) first diagnosed with ASD (autism, Asperger's or PDD-NOS) in adulthood according to current diagnostic criteria found that educational attainment was relatively high, with a quarter having completed college or university, and $43 \%$ employed or studying [31]. Half of those over 23 years were living independently. The better outcome in this study, compared to follow-ups of individuals diagnosed in childhood, may reflect the wider diagnostic criteria in current usage, which include more subtle forms of ASD. In addition, more severely affected individuals, or those with less support, are likely to reach clinical attention earlier; both of these factors will themselves effect outcome. Despite this, the authors found high life-time rates of associated psychiatric problems in this adult sample: mood disorders 53\%, anxiety 50\%, ADHD 43\%, dyslexia $14 \%$, and eating disorder $5 \%$.

High rates of psychiatric problems, particularly anxiety and depression, are a common finding in studies of adults with ASD [e.g. 32], and are discussed further below. In addition, Wing and Shah [33] have suggested that catatonia occurs disproportionately in ASD, with onset typically between 10 and 19 years. From their sample of 506 referrals to a specialist assessment centre, $6 \%$ met the authors' criteria for catatonia (increased slowness, difficulty in initiating and completing actions, reliance on prompting, passivity). This accords with estimates from Gillberg and Steffenburg's [34] follow-up study, which found a $6.5 \%$ prevalence for catatonia by the time their ASD sample reached adulthood.

Cross-sectional comparisons of younger and older individuals with ASD, however, suggest a more hopeful picture. Esbensen et al. [35], examining data from over 700 individuals with ASD aged 2-62 years (around a third over 21), concluded that restricted and repetitive behaviours of all types were less severe in older than in younger individuals with ASD. Seltzer et al. [36] also report general improvements in many symptom areas with increasing age, in their comparison of adolescents $(n=251$, $10-21$ years, mean age 15$)$ and adults $(\mathrm{n}=154,22-53$ years, mean age 31 ) with ASD. Investigating the sensory abnormalities common in ASD, Kern et al. [37] found that individuals became 'more similar' to controls as age 
increased in a sample of individuals with ASD aged 3-56 years. The authors suggest that sensory abnormalities have the potential to improve with age, but whether this improvement continues in the face of a general age-related decline in sensory processing (e.g. hearing, vision) and to what extent it may be related to this change is currently unclear.

Little is known about how the neurocognitive profile of ASD might change with age in adulthood. Extensive studies of children with ASD have established that core deficits are typical in social cognition and certain executive functions, while relative assets exist in detail-focused processing. Although these three areas have been assessed in adults with ASD, there are to date no longitudinal studies examining the trajectory of these neurocognitive markers of ASD in older adulthood. Social cognition, executive function and local-global processing have, however, been examined in studies of typical aging, and this work is discussed below in relation to the neurocognitive pattern characteristic of ASD.

\section{Normal Adult Aging in Neurocognitive Functions Implicated in ASD}

\section{Social Cognition}

Children with autism appear to show deficits in 'theory of mind', the ability to attribute mental states to self and others. These deficits go a long way towards explaining the socio-communicative difficulties shown by even highly intelligent young people with ASD. With age, some bright adolescents with ASD will come to pass standard tests of theory of mind (ToM), although they typically continue to show difficulty 'reading minds' in everyday life. In adults with ASD, differences in brain activation are seen during ToM tasks (even when performance is at normal levels) in a key network of medial prefrontal, superior temporal sulcus and temporo-parietal regions [e.g. 38].

There are few studies investigating social cognitive abilities or theory of mind in normal aging and existing studies have generated mixed results. While an early study of ToM demonstrated that older adults performed better than young adults [39], this may have reflected sampling effects. A number of later studies with wellmatched samples have shown worse ToM performance with increasing age [40-45]. It has been suggested that decline in ToM observed in aging may be explained by worsening of other cognitive abilities such as intelligence $[39,40,45]$, executive functions [40-42] or episodic memory [41].
How typical age-related declines in ToM performance relate to aging in ASD is unclear. If the same pattern is observed as in typical older adults, then further decline in ToM would be expected in aging ASD adults. However, in at least some cases of high-functioning individuals with ASD (e.g. Temple Grandin) there is anecdotal evidence to suggest that understanding of socio-cognitive situations increases with age, possibly due to increasing compensation.

\section{Executive Function}

Executive function is an umbrella term used to describe goal directed, voluntary actions, including inhibitory control, planning, initiation, and cognitive setshifting. Deficits in some executive functions have been observed in individuals with ASD, in particular in planning, generativity and cognitive set-shifting [46]. Interestingly, executive function deficits have been hypothesised to be central to age-related cognitive decline [47]. Older typically developing (TD) adults tend to be both slower and less accurate on tasks requiring cognitive setshifting, the ability to switch either between rules or away from an unsuccessful strategy $[48,49]$. For example, in a study comparing two groups of older adults, the old-old group (70-86 years) was significantly slower than the young-old group (59-69 years) on four set-shifting tasks [50]. Set-shifting is commonly impaired in individuals with ASD, although there has been some suggestion that executive functions may improve somewhat with age in ASD children and adolescents [51]. It would clearly be informative to study age-related changes in this and other executive functions in older adults with ASD.

\section{Local-Global Processing}

ASD is characterised by an uneven cognitive profile with notable strengths in, for example, the block design subtest of the Wechsler intelligence scales, and rote memory. The tendency to attend to and remember small details, while often failing to integrate information in context for meaning, has been referred to as 'weak central coherence', and is hypothesized to be the processing style or bias underlying peaks of performance and special talents in ASD [52, 53].

In normal aging, changes in global-local processing have also been reported. Lux et al. [54], using hierarchical figure tasks (e.g. a large E made of smaller Rs), found local precedence effects (faster RT to local than global targets) in older adults (mean 58 years) in contrast to the expected global precedence in the younger (22 years) 
group. They discuss their findings in relation to suggestions that the left hemisphere is preferentially biased toward local processing and ages more slowly than the right hemisphere, which is biased toward global processing. Interestingly, studies of the normal aging brain have also suggested either that the right hemisphere is more susceptible to age-effects than the left [55] or that the usual brain asymmetry is reduced in aging [56]; both of these theories suggest that left hemisphere-based local processing style may be enhanced in old age. Another study investigating age-related changes in local and global processing also demonstrated a local processing preference in older adults [57], and an association with size of the genu of the corpus callosum (carrying anterior inter-hemispheric connections). The authors suggest that this inter-hemispheric connection, which is reduced in normal aging, mediates inhibitory control underlying age-related changes in local-global processing. These studies of TD aging would appear to predict an exaggeration of the characteristic local processing bias seen in ASD, as individuals enter old age, but this remains to be tested.

\section{Memory}

Memory deficits have not been seen as a core feature of ASD; however, a growing body of research suggests that, despite good rote memory for facts and intact recognition in well-scaffolded tasks, memory is significantly impaired in ASD. The type of memory most often found to be impaired in ASD is exactly that which typically declines in normal aging: episodic memory, that is memory for information relating to personally experienced events $[58,59]$. Indeed, Bowler et al. [60] has referred to the 'aging analogy' to describe the pattern of memory functioning in children and adults with ASD. Difficulties with complex free recall tasks, diminished episodic memory, and reduced recall of incidentally-encoded context in ASD mirror the picture seen in older typically-aging individuals [see 61,62, for reviews]. In typical development, episodic memory declines significantly with age in adulthood [e.g. 63], with recall (selfgenerated responses) being more affected than recognition memory [64-66]. In typical aging, both EF and memory decline are associated with increases in depression $[67,68]$. Given the high rates of depression in ASD [e.g. 69], this association, and its possible basis in white matter degradation, may be significant and is discussed further below.

\section{Areas for Future Research}

\section{Cognitive Reserve in Aging}

The notion of cognitive reserve reflects the fact that there are individual differences in clinical presentation (symptoms) despite similar levels of damage to the brain. It has been hypothesised that these individual differences reflect some sort of 'reserve' that is protective against damage due to either injury or aging [70]. Proxy measures that have been used as indicators of reserve include higher intelligence or educational level, although other cognitive measures and socio-economic status have also been used; there is some evidence that these proxy measures mediate decline in both aging and disease states.

The mechanisms of reserve have also been associated with brain changes. It has been suggested that individuals with more cognitive reserve or larger brains ('brain reserve') can sustain more damage to brain structures before significant cognitive decline is observed [70, 71]. A perhaps more sophisticated approach describes the reserve in terms of the potential for efficient processing across cognitive networks or greater capacity in the face of increased demand [72]. It has been suggested that cognitive reserve may be associated with greater capacity for compensation as measured by altered functional activation [73].

Potential interactions between cognitive reserve and pathophysiological changes in the brain remain unclear in typical aging. In aging individuals with ASD, variations in intelligence may have a significant effect on how 'reserve' interacts with age-related cognitive declines; intelligence is known to be a major prognostic factor in ASD during childhood and early adulthood. Alternatively, the suggested larger brain volume in ASD, or differences in white matter connections measured using diffusion tensor imaging [74,75], may be protective of typical age-related brain changes.

\section{Quality of Life in Old Age}

Social isolation and loneliness have a significant negative effect on quality of life in aging. In normal older adults, social isolation is associated with greater risk of mortality [76], disability [77], depression [78] and poorer health [79]. Social isolation can be further separated into isolation (physical separation from others) and loneliness (lack of social support), two factors that are only weakly to moderately associated $[79,80]$. Typically, isolation is associated with marital status, type of social network and social class; whereas for loneliness important predictors are type of social network, household composition and health. Although in TD older adults both these factors are 
associated with poorer health, it is not clear whether the same patterns of association will hold in ASD where, for example, social isolation might be possible without perceived loneliness, if solitary hobbies and interests are motivating and fulfilling. It is unclear whether older ASD adults might be somewhat 'protected' from some of the effects of social isolation, if some individuals have never had extended social networks developed through employment and friendship groups. On the other hand, attachment to family may be strong, and individuals with ASD with fewer friendships may be even more affected than 'neurotypicals' by the loss of loved ones and shrinking family networks due to illness and immobility.

\section{White Matter Damage and Depression in Aging}

The presence of white matter hyperintensities in older TD adults has been associated with the development of depression [81, 82]. Additionally, individuals with depression associated with white matter damage display core deficits in higher-level executive functions [83]. This association, when combined with vascular risk factors, is thought to contribute to the biological profile of vascular depression [84]. A recent study has demonstrated that even in non-depressed older adults, depressive symptomatology is associated with white matter integrity measured using diffusion tensor imaging [68]. In normal aging, both physical and psychosocial well-being positively impact mood. It has been shown that stress increases the association between vascular risk and depression [85].
Given that many studies have demonstrated reduced white matter integrity in autism spectrum disorders [75, $86,87]$, this may be an additional risk factor for developing depression in older age. Whether men are in general more vulnerable than women to such age-related decline in brain structure and cognitive function [88], or whether individual differences (regardless of gender) in disruption to complex cognitive networks across the brain predict outcome [89] is open to debate. It is unclear whether the complex interaction of physiological, cognitive and psycho-social factors influencing mood will be consistent or different across TD and ASD aging.

\section{Conclusions}

In conclusion, the trajectories of change in cognitive and social functioning in ASD in old age remain unknown. It may be that declines will follow the pattern observed in TD older adults or that certain functions may be spared or continue to improve in ASD. Future studies using prospective, longitudinal methods are needed in order to identify the nature of age-related changes in behaviour, cognition and neurobiology. Such studies will be important for the planning of interventions and resources for the growing elderly population with ASD, but may additionally provide clues to the neuropathology and etiology of this complex condition.

\section{References}

1 Kanner L: Autistic disturbances of affective contact. Nervous Child 1943;2:217-249.

2 Asperger $\mathrm{H}$, translated and annotated by Frith U: 'Autistic psychopathy' in childhood; in: Autism and Asperger syndrome. Cambridge, Cambridge University Press, 1991, pp 37-92.

-3 Sukhareva GE: Die schizoiden Psychoathien in Kindesalter [Schizoid psychopathies in childhood]. Monatschrift für Psychiatrie und Neurologie, 60, 235-261. Translated in Wolff S (1996): The first account of the syndrome Asperger described? Eur Child Adolesc Psychiatry 1926;5:119-132.

4 Houston R, Frith U: Autism in History. Oxford, Blackwell, 2000.

5 Baird G, Simonoff E, Pickles A, Chandler S, Loucas T, Meldrum D, Charman T: Prevalence of disorders of the autism spectrum in a population cohort of children in South Thames: the Special Needs and Autism Project (SNAP). Lancet 2006;368:210-215.
6 Brugha T, McManus S, Meltzer H, Smith J Scott FJ, Purdon S, Harris J, Bankart J: Autism Spectrum Disorders in adults living in households throughout England: a report from the Adult Psychiatric Morbidity Survey, 2007. http://www.ic.nhs.uk/pubs/asdpsychiatricmorbidity07. 2009.

7 Murphy DGM, Beecham J, Craig M, Ecker C: Autism in adults: new biologicial findings and their translational implications to the cost of clinical services. Brain Res 2011;1380: 22-33.

>8 Gillberg C, Billstedt E, Sundh V, Gillberg IC: Mortality in autism: a prospective longitudinal community-based study. J Autism Dev Disord 2010;40:352-357.

$\checkmark 9$ Mouridsen SE, Bronnum-Hansen H, Rich B, Isager T: Mortality and causes of death in autism spectrum disorders: an update. Autism 2008; 12:403-414.
10 James IA, Mukaetova-Ladinska E, Reichelt FK, Briel R, Scully A: Diagnosing Aspergers syndrome in the elderly: a series of case presentations. Int J Geriatr Psychiatry 2006;21: 951-960.

11 Naidu A, James I, Mukaetova-Ladinska E, Briel R: Diagnosis of Asperger syndrome in a 66-year-old male presenting with depression. Int Psychogeriatr 2006;18:171-173.

12 van Niekerk MEH, Groen W, Vissers CTWM, van Driel-de Jong D, Kan CC, Oude Voshaar RC: Diagnosing autism spectrum disorders in elderly people. Int Psychogeriatr 2011;23:700-710.

$>13$ Heijnen-Kohl SM, van Alphen SP: Diagnosis of autism spectrum disorders in older adults. Tijdschr Psychiatr 2009;51:339-343.

14 Mukaetova-Ladinska EB, Perry E, Baron M, Povey C, Autism Ageing Writing Group: Ageing in people with autistic spectrum disorder. Int J Geriatr Psychiatry 2011, Epub ahead of print. 
15 Povey C, Mills R, de la Cuesta GG: Autism and ageing: issues for the future. Clin Pract 2011:230-232.

16 Wick JY, Zanni GR: Autism and aging: hardly out of the woods. Consultant Pharmacist 2009;24:648-660.

17 Stuart-Hamilton I, Griffith G, Totsika V, Nash S, Hastings RP, Felce D, Kerr M: The circumstances and support needs of older people with Autism. Report for the Welsh Assembly Government. Cardiff, Welsh Assembly. http://wales.gov.uk/docs/dhss/ report/100622olderpeoplewithautismreporten.pdf. 2009.

-18 Totsika V, Felce D, Kerr M, Hastings R: Behavior problems, psychiatric symptoms, and quality of life for older adults with intellectual disability with and without autism. J Autism Dev Disord 2010;40:1171-1178.

19 van Rooijen M: Autistische oudere lijkt niet te bestaan. Psyche (Stuttg) 2005;6:4-5.

20 van der Palen A: Autisme bij ouderen! Avans Hogeschool Breda, 2006.

-21 Underwood L, McCarthy J, Tsakanikos E: Mental health of adults with autism spectrum disorders and intellectual disability. Curr Opin Psychiatry 2010;23:421-426.

-22 Perkins EA, Moran JA: Aging Adults With Intellectual Disabilities. J Am Med Assoc 2010;304:91-92.

23 Kantrowitz B, Scelfo J: What happens when they grow up? Newsweek 2006;148:46-53.

24 Greenfield KT: How autism ages. Time 2009; 173:32-36.

25 Donovan J, Zucker C: Autism's First Child. The Atlantic 2010, October.

-26 Howlin P, Goode S, Hutton J, Rutter M: Adult outcome for children with autism. J Child Psychol Psychiatry 2004;45:212-229.

-27 Billstedt E, Carina Gillberg I, Gillberg C: Autism in adults: symptom patterns and early childhood predictors. Use of the DISCO in a community sample followed from childhood. J Child Psychol Psychiatry 2007;48: 1102-1110.

-28 Cederlund M, Hagberg B, Billstedt E, Gillberg C: Asperger syndrome and autism: a comparative longitudinal follow-up study more than 5 years after original diagnosis. J Autism Dev Disord 2008;38:72-85.

29 Hippler K: The life course of individuals with Asperger syndrome: a qualitative follow up and group study of adults formerly diagnosed by Hans Asperger in Austria and Lorna Wing in Britain; Diss, Wien, 2003.

-30 Hippler K, Viding E, Klicpera C, Happé F: No increase in criminal convictions in Hans Asperger's original cohort. J Autism Dev Disord 2010;40:774-780.

-31 Hofvander B, Delorme R, Chaste P, Nyden A, Wentz E, Stahlberg O, Herbrecht E, Stopin A, Anckarsater H, Gillberg C, Rastam M, Leboyer M: Psychiatric and psychosocial problems in adults with normal-intelligence autism spectrum disorders. BMC Psychiatry 2009;9:35.
32 Gillott A, Standen PJ: Levels of anxiety and sources of stress in adults with autism. J Intellect Disabil 2007;11:359-370.

33 Wing L, Shah A: Catatonia in autistic spectrum disorders. Br J Psychiatry 2000;176: 357-362.

34 Gillberg C, Steffenburg S: Outcome and prognostic factors in infantile autism and similar conditions: a population-based study of 46 cases followed through puberty. J Autism Dev Disord 1987;17:273-287.

35 Esbensen A, Seltzer M, Lam K, Bodfish J: Age-related differences in restricted repetitive behaviors in autism spectrum disorders. J Autism Dev Disord 2009;39:57-66.

36 Seltzer MM, Krauss MW, Shattuck PT, Orsmond G, Swe A, Lord C: The symptoms of autism spectrum disorders in adolescence and adulthood. J Autism Dev Disord 2003; 33:565-581.

37 Kern JK, Trivedi MH, Garver CR, Grannemann BD, Andrews AA, Savla JS, Johnson DG, Mehta JA, Schroeder JL: The pattern of sensory processing abnormalities in autism. Autism 2006;10:480-494.

38 Castelli F, Happe F, Frith U, Frith C: Movement and mind: a functional imaging study of perception and interpretation of complex intentional movement patterns. Neuroimage 2000;12:314-325.

39 Happé FGE, Winner E, Brownell H: The getting of wisdom: theory of mind in old age. Dev Psychol 1998;34:358-362.

40 Charlton RA, Barrick TR, Markus HS, Morris RG: Theory of mind associations with other cognitive functions and brain imaging in normal ageing. Psychol Aging 2009;24: 338-348.

41 Maylor EA, Moulson JM, Muncer A, Taylor LA: Does performance on theory of mind tasks decline in old age? Br J Psychol 2002; 93:465-485.

42 McKinnon MC, Moscovitch M: Domaingeneral contributions to social reasoning: theory of mind and deontic reasoning re-explored. Cognition 2006;102:179-218.

43 Saltzman J, Strauss E, Hunter M, Archibald $S$ : Theory of mind and executive functions in normal human aging and Parkinson's disease. J Int Neuropsychol Soc 2000;6:781-788.

44 Slessor G, Phillips LH, Bull R: Exploring the specificity of age-related differences in theory of mind tasks. Psychol Aging 2007;22: 639-643.

45 Sullivan S, Ruffman T: Social understanding: how does it fare with advancing years? Br J Psychol 2004;95:1-18.

46 Hill EL: Executive dysfunction in autism. Trends Cogn Sci 2004;8:26-32.

47 Hasher L, Zacks RT: Working memory, comprehension, and aging: a review and a new view; in Bower GH (ed): The Psychology of Learning and Motivation: Advances in Research and Theory. San Diego, Academic Press, 1988, pp 193-225.
48 Daigneault S, Braun CMJ, Whitaker HA: An empirical test of two opposing theoretical models of prefrontal function. Brain Cogn 1992;19:48-71.

49 Kane MJ, Hasher L, Stoltzfus ER, Zacks RT, Connelly SL: Inhibitory attentional mechanisms and aging. Psychol Aging 1994;9:103112.

50 Shilling V, Chetwynd A, Rabbitt P: Individual inconsistency across measures of inhibition: an investigation of the construct validity of inhibition in older adults. Neuropsychologia 2002;40:605-619.

51 Happé FGE, Booth RDL, Charlton RA, Hughes C: Executive function deficits in autism spectrum disorders and attention-deficit/hyperactivity disorder: examining profiles across domains and ages. Brain Cogn 2006;61:25-39.

52 Happé F, Frith U: The weak coherence account: detail-focused cognitive style in autism spectrum disorders. J Autism Dev Disord 2006;36:5-25.

53 Happé F, Vital P: What aspects of autism predispose to talent? Philos Trans R Soc Lond B Biol Sci 2009;364:1369-1375.

54 Lux S, Marshall JC, Thimm M, Fink GR: Differential processing of hierarchical visual stimuli in young and older healthy adults: implications for pathology. Cortex 2008;44: 21-28.

55 Dolcos F, Rice HJ, Cabeza R: Hemispheric asymmetry and aging: right hemisphere decline or asymmetry reduction. Neurosci Biobehav Rev 2002;26:819-825.

56 Cabeza R: Hemispheric asymmetry reduction in older adults: the HAROLD model. Psychol Aging 2002; 17:85-100.

57 Muller-Oehring EM, Schulte T, Raassi C, Pfefferbaum A, Sullivan EV: Local-global interference is modulated by age, sex and anterior corpus callosum size. Brain Res 2007; 1142:189-205.

58 Parkin AJ, Java RI: Determinants of age-related memory loss; in Perfect TJ, Maylor EA (eds): Models of Cognitive Aging. Debates in Psychology. London, Oxford University Press, 2000, pp 188-203.

59 Wheeler MA: Episodic Memory and Autonoetic Awareness; in Tulving E, Craik FIM (eds): The Oxford Handbook of Memory. New York, Oxford University Press, 2000, pp 597-608

60 Bowler DM, Gardiner JM, Gaigg SB: Factors affecting conscious awareness in the recollective experience of adults with Asperger's syndrome. Conscious Cogn 2007;16:124-143.

61 Boucher J, Bowler DM: Memory in Autism: Theory and Research. Cambridge, Cambridge University Press, 2008.

62 Bowler DM, Gaigg SB, Lind SE: Characteristics of memory in autism spectrum disorder; in Roth I, Rezaie P (eds): Researching the Autism Spectrum: Contemporary Perspectives. Cambridge, Cambridge University Press, 2010 
-63 Kramer JH, Yaffe K, Lengenfelder J, Delis DC: Age and gender interactions on verbal memory performance. J Int Neuropsychol Soc 2003;9:97-102.

64 Craik FIM, McDowd JM: Age differences in recall and recognition. J Exp Psychol 1987; 13:474-479.

-65 White N, Cunningham WR: What is the evidence for retrieval problems in the elderly? Exp Aging Res 1982;8:169-171.

66 Whiting WLI, Smith AD: Differential agerelated processing limitations in recall and recognition tasks. Psychol Aging 1997;12: 216-224.

67 Bunce D, Handley R, Gaines SOJ: Depression, anxiety, and within-person variability in adults aged 18 to 85 years. Psychol Aging 2008;23:848-858.

68 Lamar M, Charlton RA, Morris RG, Markus HS: The impact of subcortical white matter disease on mood in euthymic older adults: a diffusion tensor imaging study. Am J Geriatr Psychiatry 2010;18:634-642.

-69 Stewart ME, Barnard L, Pearson J, Hasan R, O’Brien G: Presentation of depression in autism and Asperger syndrome: a review. Autism 2006; 10:103-116.

70 Stern Y: What is cognitive reserve? Theory and research application of the reserve concept. J Int Neuropsychol Soc 2002;8:448460.

71 Hall CB, Derby C, LeValley A, Katz MJ, Verghese J, Lipton RB: Education delays accelerated decline on a memory test in persons who develop dementia. Neurology 2007;69:16571664.

72 Stern Y, Habeck C, Moeller J, Scarmeas N, Anderson KE, Hilton HJ, Flynn J, Sackeim $H$, van Heertum R: Brain networks associated with cognitive reserve in healthy young and old adults. Cereb Cortex 2005;15:394402 .
73 Bosch B, Bartrés-Faz D, Rami L, ArenazaUrquijo EM, Fernández-Espejo D, Junqué C, Solé-Padullés C, Sánchez-Valle R, Bargalló N, Falcón C, Molinuevo JL: Cognitive reserve modulates task-induced activations and deactivations in healthy elders, amnestic mild cognitive impairment and mild $\mathrm{Alz}$ heimer's disease. Cortex 2009;46:451-461.

74 Catani M, Jones DK, Daly E, Embiricos N, Deeley Q, Pugliese L, Curran S, Robertson D, Murphy DG: Altered cerebellar feedback projections in Asperger syndrome. Neuroimage 2008;41:1184-1191.

75 Sundaram SK, Kumar A, Makki MI, Behen ME, Chugani HT, Chugani DC: Diffusion tensor imaging of frontal lobe in autism spectrum disorder. Cereb Cortex 2008; 18: 2659-2665.

76 Shiovitz-Ezra S, Ayalon L: Situational versus chronic loneliness as risk factors for allcause mortality. Int Psychogeriatr 2010;22: 455-462.

$\checkmark 77$ Lund R, Nilsson CJ, Avlund K: Can the higher risk of disability onset among older people who live alone be alleviated by strong social relations? A longitudinal study of non-disabled men and women. Age Ageing 2010;39: 319-326.

78 Isaac V, Stewart R, Artero S, Ancelin ML, Ritchie K: Social activity and improvement in depressive symptoms in older people: a prospective community cohort study. Am J Geriatr Psychiatry 2009;17:688-696.

79 Cornwell EY, Waite LJ: Measuring social isolation among older adults using multiple indicators from the NSHAP study. J Gerontol [B] 2009;64:i38-i46.

80 Wenger GC, Davies R, Shahtahmasebi S, Scott A: Social isolation and loneliness in old age: review and model refinement. Age Society 1996;16:333-358.

-81 O’Brien JTD, Firbank MJP, Krishnan MSM, van Straaten ECWM, van der Flier WMP, Petrovic KM, Pantoni LMD, Simoni MMD, Erkinjuntti TMD, Wallin AMD, Wahlund LO, Inzitari DMD, LADIS Group: White matter hyperintensities rather than lacunar infarcts are associated with depressive symptoms in older people: the LADIS Study. Am J Geriatr Psychiatry 2006;14:834-841.
82 Firbank MJ, Lloyd AJ, Ferrier N, O’Brien JT: A volumetric study of MRI signal hyperintensities in late-life depression. Am J Geriatr Psychiatry 2004;12:606-612.

83 Alexopoulos GS, Kiosses DN, Klimstra S, Kalayam B, Bruce ML: Clinical presentation of the 'depression-executive dysfunction syndrome' of late life. Am J Geriatr Psychiatry 2002;10:98-106.

$>84$ Alexopoulos GS, Meyers BS, Young RC, Campbell S, Silbersweig D, Charlson M: 'Vascular depression' hypothesis. Arch Gen Psychiatry 1997;54:915-922.

85 Holley C, Murrell SA, Mast BT: Psychosocial and vascular risk factors for depression in the elderly. Am J Geriatr Psychiatry 2006;14: 84-90.

86 Alexander AL, Lee JE, Lazar M, Boudos R, DuBray MB, Oakes TR, Miller JN, Lu J, Jeong EK, McMahon WM, Bigler ED, Lainhart JE: Diffusion tensor imaging of the corpus callosum in autism. Neuroimage 2007;34:6173.

87 Barnea-Goraly N, Kwon H, Menon V, Eliez S, Lotspeich L, Reiss AL: White matter structure in autism: preliminary evidence from diffusion tensor imaging. Biol Psychiatry 2004;55:323-326.

88 Gur RC, Mozley PD, Resnick SM, Gottlieb GL, Kohn M, Zimmerman R, Herman G, Atlas S, Grossman R, Berretta D: Gender differences in age effect on brain atrophy measured by magnetic resonance imaging. Proc Natl Acad Sci USA 1991;88:2845-2849.

89 Sullivan EV, Rohlfing T, Pfefferbaum A: Quantitative fiber tracking of lateral and interhemispheric white matter systems in normal aging: relations to timed performance. Neurobiol Aging 2010;16:591-606. 